\title{
Covid-19 Delta Variant: A review
}

Avadhut Subhash Patil*, Radhika Ganapati Patil, Mayuri Mahadev Patil.

Rajarambapu College of Pharmacy, Kasegaon.

Rajarambapu College of Pharmacy, Kasegaon.

Rajarambapu College of Pharmacy, Kasegaon.

Phone No. 9359660991

Email id:avadhutpatil4720@gmail.com 


\begin{abstract}
Absract:
The more transmissible delta variant of the coronavirus is on track to become the dominant form globally, experts tell New Scientist. First seen in India and now in at least 85 nations, its spread has led to new lockdowns and other curbs across the world. "Globally there is a lot of concern about the delta variantCurrently, delta is recorded as the second most dominant variant of concern globally. It binds to the ACE-2 receptor, which is located in the heart, lungs, kidneys, and gastrointestinal system, making viral entrance into target cells easier.Manyproctative stapes has been taken worldwide against SARS-COV- 2 pandimuc and praventcovid 19 spread with realistic approches.
\end{abstract}

Keywords: coronavirus, SARS-COV -2, Delta variant (B.1.617.2), angiotensin-converting enzyme 2(ACE-2).

\title{
Introuction:
}

The deadly SARS-CoV-2 (Severe Acute Respiratory Syndrome Corona Virus-2) has a devastating effect on human life.The coronavirus illness in 2019 is caused by the severe acute respiratory syndrome coronavirus 2 (SARS-CoV2) (COVID-19).It's summer, and we're witnessing another surge in COVID-19 infections across the country, as expected.From a low point in June, cases have risen across the country.Governments are taking significant measures to speed up the vaccination campaign in order to manage the epidemic globally.However, because of its positivesense single-stranded RNA genetic material, SARS-CoV-2 has a high mutation rate, posing a public health threat.Different highly infectious forms of SARS-CoV-2 emerged as a result of mutations in the SARS-CoV-2 genome (VOCs).India (B.1.617.2; VOC-21APR-02), for example, is more transmissible than the early 2020 versions.In terms of viral pathogenicity, virulence, and transmission, the variations of concern (VOCs) are crucial.Variants of concern (VOCs) such as (B.1.1.7, B.1.351, B.1.617.2) are more transmissible, resulting in likely higher disease severity outcomes, and are also known for lower antibody neutralisation sensitivity. ${ }^{[1]}$

\section{Investigation:}

In the United States, the Delta variety, which accounted for $10 \%$ of illnesses in early June but over $100 \%$ of new cases by August 2021, travels faster than the original virus and might spread as swiftly as Alpha.Spike has the L452R and P681R mutations, whereas Kappa has T478K but not E484Q.Public Health England announced on June 3, 2021, that twelve of the 42 deaths in England due to the Delta strain were among the fully vaccinated, and that it was spreading nearly twice as rapidly as the Alpha version. Also on 11 June, Foothills Medical Centre in Calgary, Canada, reported that half of their 22 Delta variant cases were among fully vaccinated individuals. Reports of a Delta variant with the K417N mutation began to surface in June 2021. The mutation, which was also found in the Beta and Gamma types, aroused fears that vaccinations and antibody therapies would be less efficient, as well as an increased risk of reinfection. Public Health England has dubbed the variation "Delta with K417N," and it consists of two clades that correspond to Pango lineages AY.1 and AY.2. From "Delta plus K417N," it has been dubbed "Delta plus." After 22 cases of the "Delta plus" version of COVID-19 were detected in India, India's Ministry of Health and Family Welfare labelled it a Variant of Concern on June 22. Leading virologists claimed there was insufficient evidence to warrant labelling the variation as a unique variety of concern after the release, citing the limited number of individuals tested. 


\section{History :}

It's summer, and as predicted, we're seeing yet another spike in COVID-19 infections around the nation. Cases have increased across the country from a trough in June. A large part of the increase can be traced to the convergence of two factors in late April. One, the Delta variety's rapid spread in the United States, where it accounted for $10 \%$ of infections in early June but over 100\% of new cases by August 2021, exceeding the previously dominant Alpha form. Two, this occurred immediately after several governments lifted mask restrictions, allowing the new strain to spread uncontrolled. Despite the fact that vaccines are now widely available and that $70 \%$ of the adult population has been partially vaccinated, many people are still at risk due to vaccine rejection, vaccine hesitancy, vaccine access issues, or lack of eligibility (vaccines are not authorised for anyone under the age of 12.A spate of new variants of SARS-CoV-2 was detected in multiple countries in the fall and winter of 2020. The Delta variant (also known as B.1.617.2) was one of these which emerged and spread globally. Many mutations will be either neutral or harmful to a virus. But occasionally, a mutation or combination of mutations can allow the virus to infect a host more efficiently. Some variants may also cause more severe disease in the host, as was suggested with the Alpha variant, B.1.1.7.If these variants increase in the population, the World Health Organization (WHO) or other health agencies may start calling them "variants of concern." A variant of concern designation is given for one or more of several reasons. The combination of mutations in a variant lineage may lead to increased transmissibility or increased virulence (or both). It could result in a variant that is not recognized by current diagnostic measures. Variants of concern may also show reduced effectiveness to vaccines or treatments. There are currently four designated variants of concern: Alpha (B.1.1.7, first identified in the United Kingdom), Beta (B.1.351, first identified in South Africa), Gamma (P.1, first identified in Brazil), and Delta (B.1.617.2, first identified in India). ${ }^{[2,3]}$

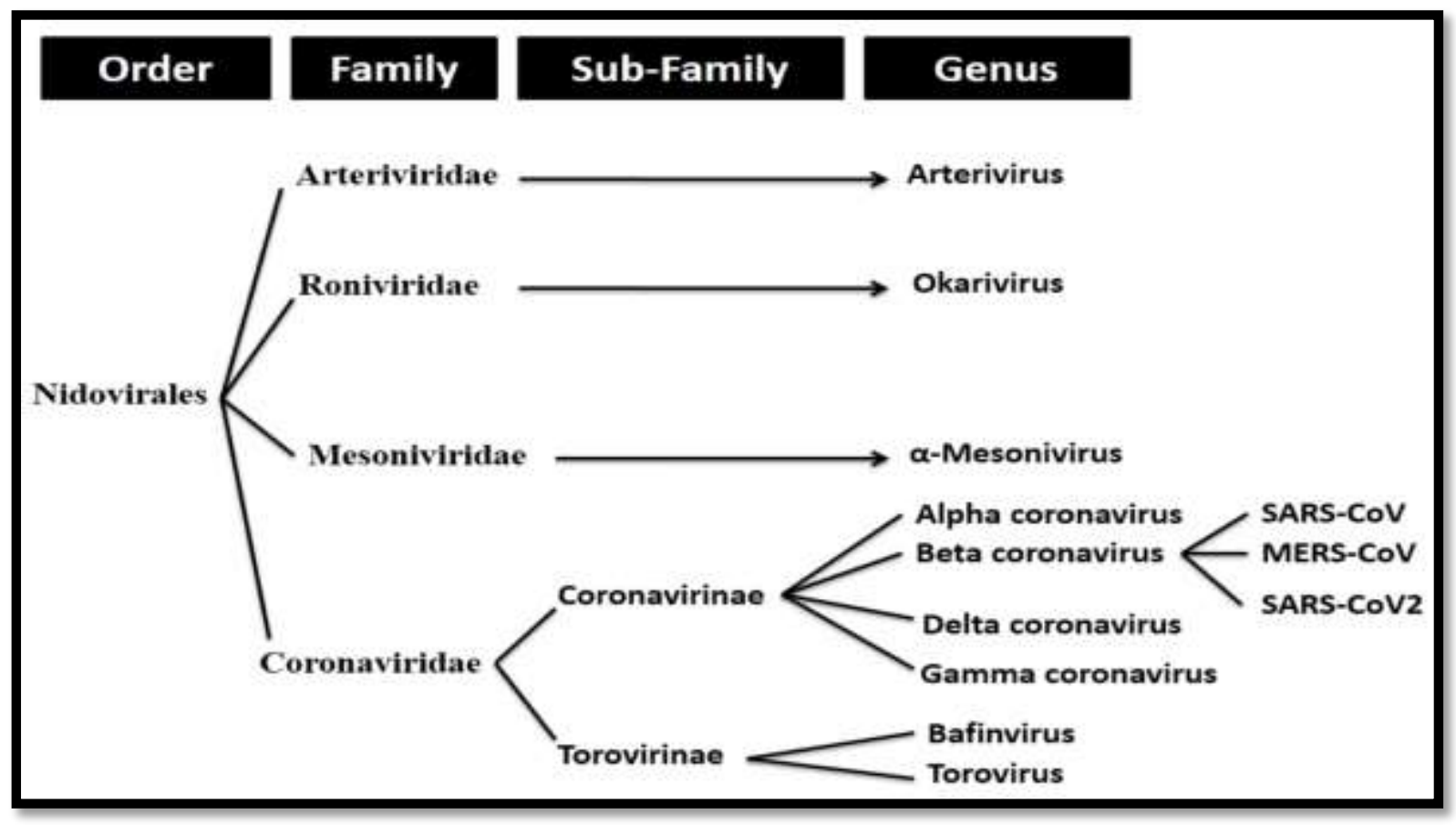

Figure 1.Classification of corona viruses. 
The SARS-CoV-2 belongs to Betacoronavirus, a member of the subfamily Coronavirinae having four genera: Alphacoronavirus, Betacoronavirus, Gammacoronavirus, and Deltacoronavirus in family Coronaviridae, categorized in the order Nidovirales.

\section{The Origin of SARS-CoV-2:}

All coronaviruses that have caused diseases to humans have had animal origins-generally either in bats or rodents.Previous outbreaks of betacoronaviruses in humans involved direct exposure to animals other than bats. In the case of SARS-CoV and MERS-CoV, they were transmitted directly to humans from civet cats and dromedary camels respectively .

Spike proteins with a varied receptor-binding domain protect coronaviruses associated to SARS (RBD). This RBD binds to the ACE-2 receptor, which is located in the heart, lungs, kidneys, and gastrointestinal system, making viral entrance into target cells easier. The RBD of SARS-CoV-2 appears to be a modified variant of its most closely related virus, RaTG13, collected from bats, according to genomic sequencing (Rhinolophusaffinis).It is, therefore, believed that the SARS-CoV-2 also originated from bats and, after mutating, was able to infect other animals. The mutation increased the RBD affinity to ACE-2 in humans, but also other animals such as ferrets and Malayan pangolins (Manisjavanica; a long-snouted, ant-eating mammal sold illegally for use in traditional Chinese medicine), but also decreased the RBD affinity to ACE-2 found in rodents and civets. The pangolin is thought to be SARSintermediate CoV-2's host. There was some early conjecture that SARS-CoV-2 was the result of a manufactured modification of an existing coronavirus, however there is no evidence to back this up. In fact, Anderson et al. claim that the mutation discovered in the RBD of SARS-CoV-2 is not the same as what would have been expected using earlier genetic approaches. "It is currently impossible to establish or deny the alternative possibilities of [the SARSCoV-2]genesis,"theauthors said. ${ }^{[4]}$

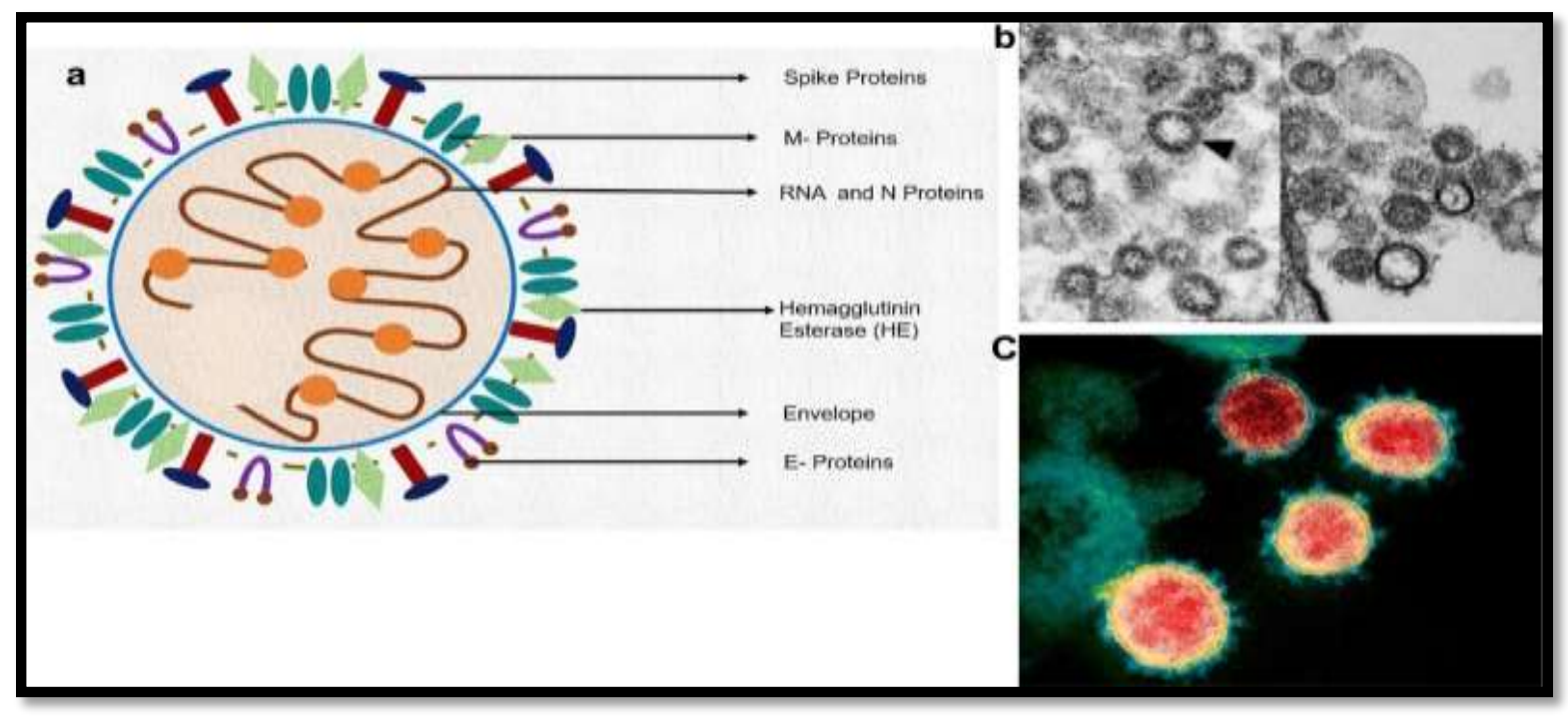

Figure 2. Structure of SARS-COV2 


\section{Pathogenesis and Clinical Presentation:}

Since SARS-CoV and SARS-CoV-2 are so similar, the biochemical interactions and the pathogenesis are likely similar. Binding of the SARS-CoV to the angiotensin-converting enzyme 2 (ACE-2) receptors in the type II pneumocytes in the lungs triggers a cascade of inflammation in the lower respiratory tract. When the SARS spike protein binds to the ACE- 2 receptor, the complex is proteolytically processed by the type 2 transmembrane protease TMPRSS2, resulting in ACE-2 cleavage and spike protein activation (Figure 3B), a mechanism similar to that used by influenza and human metapneumovirus, facilitating viral entry into the target cell . It has been suggested that cells in which ACE-2 and TMPRSS2 are simultaneously present are most susceptible to entry by SARS-CoV. Early indications are that SARS-CoV-2 virus also requires ACE-2 and TMPRSS2 to enter cells. ${ }^{[4]}$
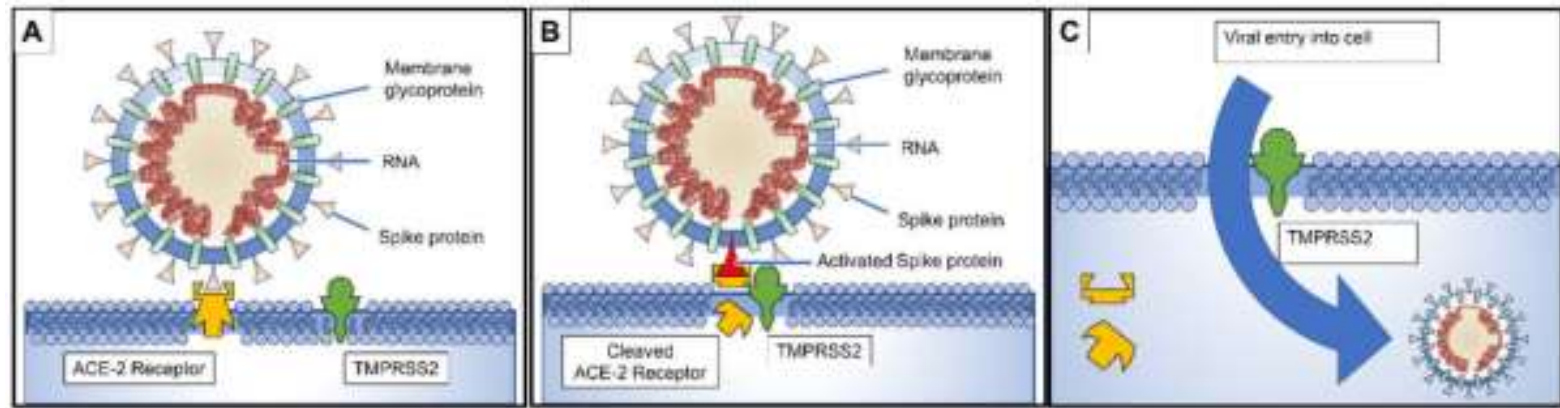

Figure 3. (A) Spike proteins on the surface of corona virus bind to ACE-2 receptoron the surface of target cell (B) the type II transmembrane serine protease binds and cleaves the ACE-2 receptor (C) cleaved ACE-2 and activated spike protein facilitate viral entry .

Pathophysiology of SARS-CoV-2:

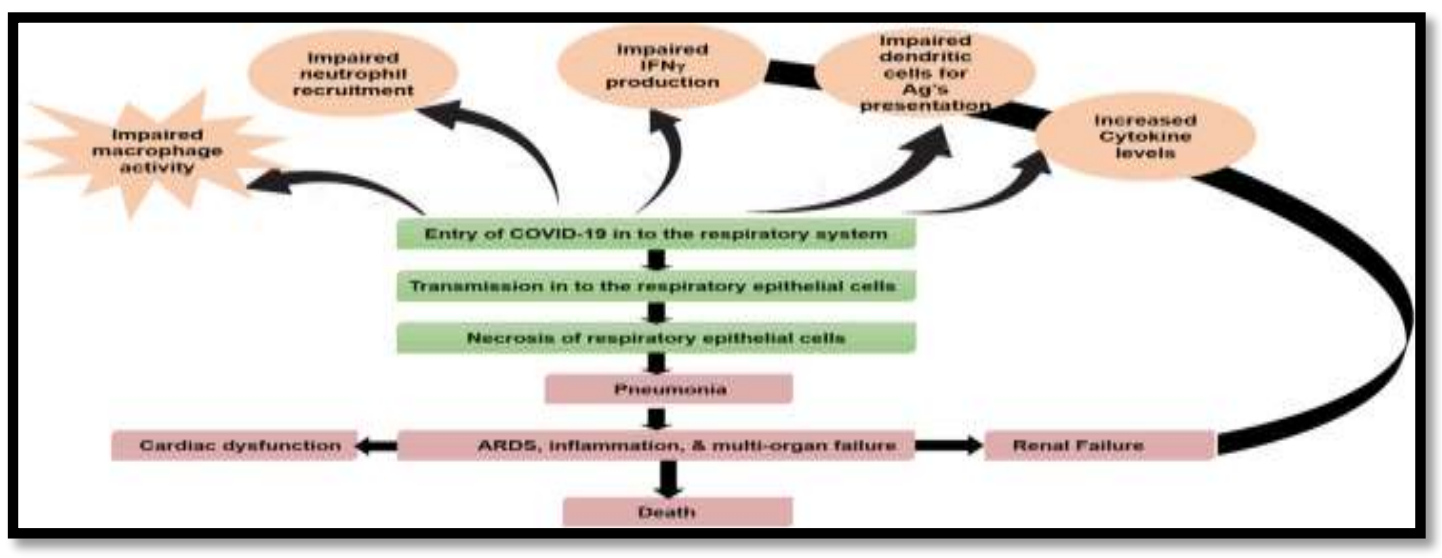

Figure 4.Pathophysiology of SARS-CoV-2 
The route of transmission of SARS-CoV-2 could be coughing and sneezing. The virus enters the lungs through the respiratory tract and attacks alveolar epithelial type 2 (AT2) cells.AT2 produces a surfactant to decrease the surface tension within alveoli to reduce the collapsing pressure.. ACE2 receptors are also found on the tubular epithelium of the kidney, heart, enterocytes, pancreas, and endothelial cells .Hoffmann et al. demonstrated the role of ACE2 and TMPRSS2 (cellular serine protease) in SARS-CoV-2 entry into the host cell. Integrins may also induce conformational changes in the ACE2 receptor during its interaction with SARS-CoV-2. Once inside the host cell, the virus releases its positive sense ssRNA. The ssRNA uses the host cell ribosome to produce polyproteins. It also uses RNA dependent RNA polymerases to duplicate its RNA. The packaging structure of the cell distributes synthesized spike proteins to vesicle carriers. The proteinases in the cytoplasm cleave the synthesized polyproteins (nucleocapsid enzymes, spike proteins, M-protein, E-protein, etc.) of SARS-CoV-2. The virus also releases specific inflammatory mediators to stimulate macrophages .Activated macrophages release cytokines (IL-1, IL-6, and TNF $\alpha$ ) and chemokines (CXCL10 and CCL2) into the bloodstream. The release of these molecules causes vasodilation and increased capillary permeability. The leakage of plasma into the interstitial spaces of the alveoli cells will accumulate around the alveoli and compress it. As a result, there is a decrease in surfactant levels in AT2 cells. The cascade events ultimately lead to alveolar collapse and impaired gaseous exchange. Concurrently, there is an increase in inflammatory cytokine (cytokine storm) secretion. The inflammatory mediators, through CD4+ T helper (Th1) cells, enhance the production and recruitment of neutrophils and macrophages using IL-17, IL-21, and IL-22. In the later stages of the disease, all these steps cause difficulty in breathing, hypoxemia, and cough. The hypothalamus controls body temperature. The released IL-1, IL6, and TNF- $\alpha$ will travel in the blood and affect the hypothalamus. They will trigger the release of prostaglandin, PGE2, and causes an increase in body temperature. Considering the hypoxic condition, sympathetics can induce tachycardia. All these abnormal inflammatory responses can lead to septic shock and multi-organ failure.[In short, due to pneumonia, the vasodilation that decreases effective blood volume (BV) and peripheral resistance (PR) can lead to hypotension, reduced perfusion rate of the heart, and multi-organ failure.$^{[5,6,7,8,9]}$

\section{Genome and proteome of SARS-CoV-2:}

Wuhan/IVDCHB-01/2019 (HB01), Wuhan/IVDCHB-04/2019 (HB04), and Wuhan/IVDCHB-05/2019 (HB05) are three strains of the new coronavirus with only five nucleotide changes in their whole genome. The SARS-CoV-2 genome has 14 open reading frames (ORFs) and encodes 27 proteins. The $5^{\prime}$ terminus ORFs (Orflab and orfla) encodes pp1 proteins and 15 nonstructural protein sequences (nsps). The 3'-terminus of the SARS-CoV-2 genome contains S, M, E, and N structural proteins and accessory proteins-3a, 3b, p6, 7a. 7b, 8b, 9b, and orf14. Interestingly, at the amino acid level, SARS-CoV-2 is almost identical to SARS-CoV. It only has a few minor differences. For example, the 8a protein is present in SARS-CoV-2 but is absent in SARS- CoV. The $8 \mathrm{~b}$ protein is longer in SARSCoV-2 (121 amino acids) than in SARS-CoV (84 amino acids). The $3 \mathrm{~b}$ protein is smaller in SARS-CoV-2 (22 amino acids) than in SARS-CoV (154 amino acids). ${ }^{[5]}$ 


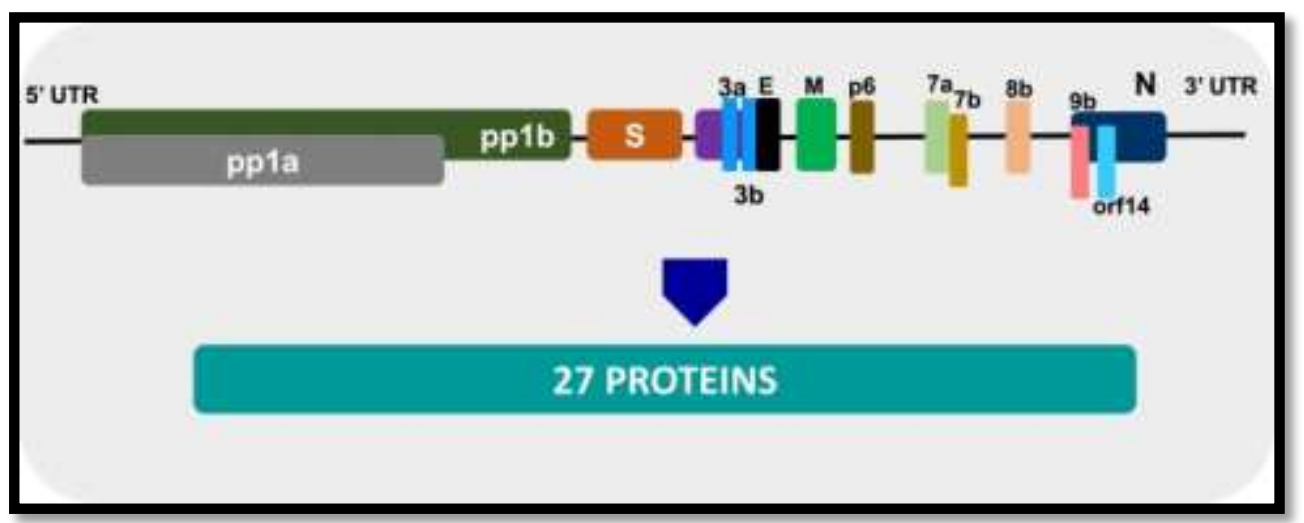

Figure 5. Genome of SARS-COV2

\section{Classification:}

\section{VARIANTS OF CONCERN}

Established to have attributes that make them 'fitter' than the first version of the virus

\begin{tabular}{|c|c|c|c|c|}
\hline $\begin{array}{l}\text { NEW WHO } \\
\text { LABEL }\end{array}$ & $\begin{array}{l}\text { PANGO UNEAGE } \\
\text { MOST COM MONLY } \\
\text { USED CODE) }\end{array}$ & $\begin{array}{l}\text { FIRST } \\
\text { FOUND IN }\end{array}$ & $\begin{array}{l}\text { DAIE OF } \\
\text { DESIGNATION }\end{array}$ & $\begin{array}{l}\text { CONCERN } \\
\text { BECAUSE }\end{array}$ \\
\hline ALPHA & B.1.1.7 & $\begin{array}{l}\text { UK (Kent); } \\
\text { Sestember, } 2020\end{array}$ & $\begin{array}{l}\text { Det 18, } 2020 \\
\text { vOC }\end{array}$ & $\begin{array}{l}\text { Sortads more rapidly than } \\
\text { predominant virus }\end{array}$ \\
\hline BETA & B.1.35 & $\begin{array}{l}\text { South Aficica: May, } \\
2020\end{array}$ & Dec 18, 2020 & $\begin{array}{l}\text { Shows significant } \\
\text { resistance }\end{array}$ \\
\hline GAMMA & $P_{1}$ & $\begin{array}{l}\text { Brazit, Noventer } \\
2020\end{array}$ & $\operatorname{Jan} 11,2021$ & $\begin{array}{l}\text { Shows some resistance, } \\
\text { enhanced infectivity }\end{array}$ \\
\hline DELTA & B.1.617. & $\begin{array}{l}\text { India; October, } \\
2020\end{array}$ & May 11,2021 & $\begin{array}{l}\text { Significantly more transmi- } \\
\text { ssible; somewhat resistant }\end{array}$ \\
\hline
\end{tabular}

\section{VARIANTS OF INTEREST}

These are being investigated by scientists at present

\begin{tabular}{|c|c|c|c|c|}
\hline $\begin{array}{l}\text { NEW WHO } \\
\text { LABEL }\end{array}$ & $\begin{array}{l}\text { PANGO UNEAGE } \\
\text { (MOSI COMENONIY } \\
\text { USED CODE) }\end{array}$ & $\begin{array}{l}\text { FIRST } \\
\text { FOUND IN }\end{array}$ & $\begin{array}{l}\text { DATE OF } \\
\text { DESIGNATION }\end{array}$ & $\begin{array}{l}\text { CONCERN } \\
\text { BECAUSE }\end{array}$ \\
\hline EPSILON & B.1.427/B.1.429 & $\begin{array}{l}\text { US (Califomia); } \\
\text { March, 2020 }\end{array}$ & March 5, 2021 & $\begin{array}{l}\text { May be more } \\
\text { transmissible }\end{array}$ \\
\hline ZETA & P.2 & Brazil, April 2020 & March 12,2021 & $\begin{array}{l}\text { May be more } \\
\text { resistant }\end{array}$ \\
\hline ETA & B.1.525 & $\begin{array}{l}\text { Muitiple countries: } \\
\text { Dec, } 2020\end{array}$ & March 17, 2021 & $\begin{array}{l}\text { May be more resistant to } \\
\text { vacines }\end{array}$ \\
\hline THETA & P.3 & $\begin{array}{l}\text { Philippines; Jan, } \\
\text { 2021 }\end{array}$ & $\begin{array}{l}\text { March 24, } \\
2021\end{array}$ & $\begin{array}{l}\text { Has some of the same } \\
\text { mutations as the other VOC }\end{array}$ \\
\hline IOTA & B.1.526 & $\begin{array}{l}\text { US (New Yorkt, } \\
\text { Nov, } 2020\end{array}$ & $\begin{array}{l}\text { March } 24, \\
2021\end{array}$ & $\begin{array}{l}\text { May be more } \\
\text { resistant }\end{array}$ \\
\hline KAPPA & B.1.617. & $\begin{array}{l}\text { india, October, } \\
2020\end{array}$ & April 4, 2021 & $\begin{array}{l}\text { May be more resistant, } \\
\text { spread more readily }\end{array}$ \\
\hline
\end{tabular}

Figure 6.classification of corona viruses 


\section{Viruses constantly change through mutation:}

A variant has one or more mutations that differentiate it from other variants in circulation. As expected, multiple variants of SARS-CoV-2 have been documented in the United States and globally throughout this pandemic. To inform local outbreak investigations and understand national trends, scientists compare genetic differences between viruses to identify variants and how they are related to each other. ${ }^{[10,11]}$

\section{Variant classifications:}

The US Department of Health and Human Services (HHS) established a SARS-CoV-2 Interagency Group (SIG) to improve coordination among the Centers for Disease Control and Prevention (CDC), National Institutes of Health (NIH), Food and Drug Administration (FDA), Biomedical Advanced Research and Development Authority (BARDA), and Department of Defense (DoD). This interagency group is focused on the rapid characterization of emerging variants and actively monitors their potential impact on critical SARS-CoV-2 countermeasures, including vaccines, therapeutics, and diagnostics. ${ }^{[10,11]}$

Variant of Interest (VOI) - View current VOI in the United States that are being monitored and characterized

Variant of Concern (VOC)- View current VOC in the United States that are being closely monitored and characterized by federal agencies

Variant of High Consequence (VOHC) - Currently there are no SARS-CoV-2 variants that rise to the level of high consequence

\section{Variant of Interest:}

A variant with specific genetic markers that have been associated with changes to receptor binding, reduced neutralization by antibodies generated against previous infection or vaccination, reduced efficacy of treatments, potential diagnostic impact, or predicted increase in transmissibility or disease severity. ${ }^{[10,11]}$

Possible attributes of a variant of interest:

Specific genetic markers that are predicted to affect transmission, diagnostics, therapeutics, or immune escape.Evidence that it is the cause of an increased proportion of cases or unique outbreak clusters.Limited prevalence or expansion in the US or in other countries.A variant of interest might require one or more appropriate public health actions, including enhanced sequence surveillance, enhanced laboratory characterization, or epidemiological investigations to assess how easily the virus spreads to others, the severity of disease, the efficacy of therapeutics and whether currently authorized vaccines offer protection.Current variants of interest in the United States that are being monitored and characterized are listed below. This will be updated when a new variant of interest is identified.Selected Characteristics of SARS-CoV-2 Variants of Interest. ${ }^{[10,11]}$

\section{WHO Label: None}

Pango Lineage: B.1.427 (Pangolineageexternal icon)

Spike Protein Substitutions: L452R, D614G

Name (Nextstrainexternal icon): 20C/S:452R 
First Identified: United States-(California)

\section{Attributes:}

20\% increased transmissionModest decrease in susceptibility to the combination of bamlanivimab and etesevimab; however, the clinical implications of this decrease are not known. Alternative monoclonal antibody treatments are available.Reduced neutralization by convalescent and post-vaccination sera.Deescalated from a VOC on June 29 , 2021, due to the significant decrease in the proportion of B.1.427 lineage viruses circulating nationally and available data indicating that vaccines and treatments are effective against this variant. ${ }^{[10,11]}$

2. WHO Label: None

Pango Lineage: B.1.429 (Pangolineageexternal icon)

Spike Protein Substitutions: S13I, W152C, L452R, D614G

Name (Nextstrainexternal icon): 20C/S:452R

First Identified: United States-(California)

Attributes:

$\sim 20 \%$ increased transmission reduced susceptibility to the combination of bamlanivimab and etesevimab; however, the clinical implications of this decrease are not known. ${ }^{7}$ Alternative monoclonal antibody treatments are available .Reduced neutralization by convalescent and post-vaccination sera. Deescalated from a VOC on June 29, 2021, due to the significant decrease in the proportion of B.1.429 lineage viruses circulating nationally and available data indicating that vaccines and treatments are effective against this variant. ${ }^{[10,11]}$

3. WHO Label: Eta

Pango Lineage: B.1.525 (Pangolineageexternal icon)

Spike Protein Substitutions: A67V, 69del, 70del, 144del, E484K, D614G, Q677H, F888L

Name (Nextstrainexternal icon): 20A/S:484K

First Identified: United Kingdom/Nigeria - December 2020

\section{Attributes:}

Potential reduction in neutralization by some Emergency Use Authorization (EUA) monoclonal antibody treatments Potential reduction in neutralization by convalescent and post-vaccination sera. ${ }^{[10,11]}$ 
4. WHO Label: Iota

Pango Lineage: B.1.526 (Pangolineageexternal icon)

Spike Protein Substitutions: L5F, (D80G*), T95I, (Y144-*), (F157S*), D253G, (L452R*), (S477N*), E484K, D614G, A701V, (T859N*), (D950H*), (Q957R*)

Name (Nextstrainexternal icon): 20C/S:484K

First Identified: United States (New York) - November 2020

BEI Reference Isolate ${ }^{\mathbf{c}}:$ NR-55359external icon

\section{Attributes:}

Reduced susceptibility to the combination of bamlanivimab and etesevimab monoclonal antibody treatment; however, the clinical implications of this are not known. ${ }^{7}$ Alternative monoclonal antibody treatments are available.Reduced neutralization by convalescent and post-vaccination sera. ${ }^{[10,11]}$

5. WHO Label: Kappa

Pango Lineage: B.1.617.1 (Pangolineageexternal icon)

Spike Protein Substitutions: (T95I), G142D, E154K, L452R, E484Q, D614G, P681R, Q1071H

Name (Nextstrainexternal icon): 20A/S:154K

First Identified: India - December 2020

\section{Attributes:}

Potential reduction in neutralization by some EUA monoclonal antibody treatmentsPotential reduction in neutralization by post-vaccination sera. ${ }^{[10,11]}$

6. WHO Label: None

Pango Lineage: B.1.617.3 (Pangolineageexternal icon) 
Spike Protein Substitutions: T19R, G142D, L452R, E484Q, D614G, P681R, D950N

Name (Nextstrainexternal icon): 20A

First Identified: India - October 2020

\section{Attributes:}

Potential reduction in neutralization by some EUA monoclonal antibody treatmentsPotential reduction in neutralization by post-vaccination sera ${ }^{[10,11]}$

\section{Variant of Concern:}

The B.1.1.7 (Alpha), B.1.351 (Beta), B.1.617.2 (Delta), and P.1 (Gamma) variants circulating in the United States are classified as variants of concern ${ }^{[10,11]}$

\section{Variant of Concern:}

A variant for which there is evidence of an increase in transmissibility, more severe disease (e.g., increased hospitalizations or deaths), significant reduction in neutralization by antibodies generated during previous infection or vaccination, reduced effectiveness of treatments or vaccines, or diagnostic detection failures. ${ }^{[10,11]}$

1. WHO Label: Delta

Pango Lineage: B.1.617.2, AY.1, AY.2, AY.3 (Pangolineageexternal icon)

Spike Protein Substitutions: T19R, (V70F*), T95I, G142D, E156-, F157-, R158G, (A222V*), (W258L*), (K417N*), L452R, T478K, D614G, P681R, D950N $\mathrm{N}^{[10,11]}$

2. WHO Label: Alpha

Pango Lineage: B.1.1.7 (Pangolineageexternal icon) ${ }^{\mathrm{a}}$

Spike Protein Substitutions: 69del, 70del, 144del, (E484K*), (S494P*), N501Y, A570D, D614G, P681H, T716I, S982A, D1118H (K1191N*)

Name (Nextstrainexternal icon) $)^{\mathrm{b}}: 20 \mathrm{I} / 501 \mathrm{Y} . \mathrm{V} 1$

First Identified: United Kingdom

BEI Reference Isolate ${ }^{\mathrm{c}}$ : NR-54000external icon

\section{Attributes:}


$\sim 50 \%$ increased transmission Potential increased severity based on hospitalizations and case fatality ratesNo impact on susceptibility to EUA monoclonal antibody treatmentsMinimal impact on neutralization by convalescent and post-vaccination sera. ${ }^{[10,11]}$

3. WHO Label: Beta

Pango Lineage(s): B.1.351, B.1.351.2, B.1.351.3 (Pangolineageexternal icon)

Spike Protein Substitutions: D80A, D215G, 241del, 242del, 243del, K417N, E484K, N501Y, D614G, A701V

Name (Nextstrainexternal icon): 20H/501.V2

First Identified: South Africa

BEI Reference Isolate ${ }^{\mathfrak{c}}:$ NR-55282external icon

\section{Attributes:}

50\% increased transmissionSignificantly reduced susceptibility to the combination of bamlanivimab and etesevimab monoclonal antibody treatment, but other EUA monoclonal antibody treatments are available Reduced neutralization by convalescent and post-vaccination seraIncreased transmissibilityPotential reduction in neutralization by some EUA monoclonal antibody treatmentsPotential reduction in neutralization by postvaccination. ${ }^{[10,11]}$

\section{WHO Label: Gamma}

Pango Lineage(s): P.1, P.1.1, P.1.2 (Pangolineageexternal icon)

Spike Protein Substitutions: L18F, T20N, P26S, D138Y, R190S, K417T, E484K, N501Y, D614G, H655Y, T1027I

Name (Nextstrainexternal icon): 20J/501Y.V3

First Identified: Japan/Brazil

BEI Reference Isolate: NR-54982external icon

\section{Attributes:}

Significantly reduced susceptibility to the combination of bamlanivimab and etesevimab monoclonal antibody treatment, but other EUA monoclonal antibody treatments are available Reduced neutralization by convalescent and post-vaccination seraFootnotes for Variants of Concern. ${ }^{[10,11]}$ 
Currently, there are no SARS-CoV-2 variants that rise to the level of high consequence for healthcare practitioners, there are a few things to think about when it comes to treatment.Concerning Substitutions in SARS-CoV-2 Monoclonal Antibody TherapiesIn the United States, the FDA has approved three anti-SARS-CoV-2 monoclonal antibody therapies for the treatment of COVID-19: bamlanivimab plus etesevimabexternal icon, casirivimab plus imdevimab,external icon, and sotrovimabexternal icon.CDC's national genomic surveillance program identifies new and emerging SARS-CoV-2 variants to determine implications for COVID-19 diagnostics, treatments, or vaccines authorized for use in the United States. Sequences with similar genetic changes are grouped into lineages, and multiple lineages can have the same substitutions. For example, the E484K substitution is found in lineages B.1.351, P.1, B.1.526, and many others. Genomic surveillance efforts provide the capability to detect viruses that have reduced susceptibility to treatments more quickly.In laboratory studies, SARS-CoV-2 variants that contain certain substitutions in the spike protein cause a marked reduction in susceptibility to bamlanivimab and may have reduced sensitivity to etesevimab and casirivimab. The L452R substitution found in the B.1.427 and B.1.429 lineages has been shown to cause a significant reduction in susceptibility to bamlanivimab and a modest decrease in susceptibility to the combination of bamlanivimab and etesevimab, although the clinical implications of this modest decrease are not known. The E484K substitution found in the B.1.351, P.1, and B.1.526 lineages also results in a marked reduction in susceptibility to bamlanivimab, as well as the combination of bamlanivimab and etesevimab.Laboratory studies also suggest that the K417N and K417T substitutions, which are present in the B.1.351 and P.1 variants, respectively, along with the E484K mutation, reduces virus susceptibility to casirivimab, although the combination of casirivimab and imdevimab appears to retain activity.There is no reported reduction in susceptibility of variants to sotrovimab. ${ }^{[10,11]}$

\section{Recombination Events in Newly Emerged Coronavirus :}

Our recombination detection programme (RDP) study showed that Wuhan-Hu-1-CoV might be a recombinant of SARS (GZ02, Rf1), SARS-like (ZXC21, ZC45, W1V1), and MERS-CoVs based on nine locations in the whole genome nucleotide sequences of Wuhan-Hu-1-CoV. The PHI-test revealed that recombination had occurred (p-value 0.00001). Furthermore, the similarity plot revealed that Wuhan-Hu-1-CoV has a 5-genomic area.

Shared a mixture of SARS and SARS-like CoVs nucleotide sequences, whereas the 3-genomic region shared a mixture of SARS and SARS-like CoVs nucleotide sequences. Our findings show that the majority of recombination events in Wuhan-Hu-1-CoV occurred in the spike glycoprotein motif, primarily at the 5'end of the S gene. In RNAdependent RNA polymerase, helicase, and ORF3a, just one recombination event was found ${ }^{[12,13]}$.

\section{Symptoms:}

Anyone with symptoms of COVID-19 should get a COVID19 test, even if the symptoms are mild.Further testing is required to determine which type of variant a person has once they have tested positive to COVID19.Symptomsusually appear five to six days after a person has been infected with COVID-19, however symptoms may appearbetween two and 14 days after exposure ${ }^{[15]}$. 


\section{References}

1. Joshi M, Kumar M, Srivastava V, Kumar D, Rathore D, Pandit R, Joshi CG. First detection of SARS-CoV-2 Delta variant (B. 1.617. 2) in the wastewater of (Ahmedabad), India.medRxiv.2021 Jan 1.

2.https://r.search.yahoo.com/_ylt=AwrxhWZ_Z1VhTDAAhAfnHgx.;_ylu=Y29sbwMEcG9zAzEEdnRpZAME $\mathrm{c} 2 \mathrm{VjA} 3 \mathrm{Ny} / \mathrm{RV}=2 / \mathrm{RE}=1633015808 / \mathrm{RO}=10 / \mathrm{RU}=\mathrm{https} \% 3 \mathrm{a} \% 2 \mathrm{f} \% 2 \mathrm{fwww}$.self.com\%2fstory $\% 2$ fdelta-plus-deltavariant-questions/RK=2/RS=ry9F0LpwuooN8epqICSAzoDSdvU-www.self.com > story > delta-plus-deltavariant 'Delta Plus' Variant: How Much Do You Need to Worry? And ...

3. Shafique L, Ihsan A, Liu Q. Evolutionary trajectory for the emergence of novel coronavirus SARS-CoV-2. Pathogens. 2020 Mar;9(3):240.

4.Rabi FA, Al Zoubi MS, Kasasbeh GA, Salameh DM, Al-Nasser AD. SARS-CoV-2 and coronavirus disease 2019: what we know so far. Pathogens. 2020 Mar;9(3):231.

5.Vallamkondu J, John A, Wani WY, Ramadevi SP, Jella KK, Reddy PH, Kandimalla R. SARS-CoV-2 pathophysiology and assessment of coronaviruses in CNS diseases with a focus on therapeutic targets. BiochimicaetBiophysicaActa (BBA)-Molecular Basis of Disease. 2020 Oct 1;1866(10):165889.

6.Wu A., Peng Y., Huang B., Ding X., Wang X., Niu P., Meng J., Zhu Z., Zhang Z., Wang J., Sheng J., Quan L., Xia Z., Tan W., Cheng G., Jiang T. Genome composition and divergence of the novel coronavirus (2019-nCoV) originating in China. Cell Host Microbe. 2020;27:325-328. [PMC free article] [PubMed] [Google Scholar] (genome)

7. Wang Q., Zhang Y., Wu L., Niu S., Song C., Zhang Z., Lu G., Qiao C., Hu Y., Yuen K.Y., Wang Q., Zhou H., Yan J., Qi J. Structural and functional basis of SARS-CoV-2 entry by using human ACE2. Cell. 2020;181(4):894-904. doi: 10.1016/j.cell.2020.03.045. e9. [PMC free article] [PubMed] [CrossRef] [Google Scholar] (patho)

8. Li Z., Tomlinson A.C., Wong A.H., Zhou D., Desforges M., Talbot P.J., Benlekbir S., Rubinstein J.L., RiniJ.M.The human coronavirus HCoV-229E S-protein structure and receptor binding. eLife. 2019;8 [PMC free article] [PubMed] [Google Scholar](patho)

9. Hoffmann M., Kleine-Weber H., Schroeder S., Kruger N., Herrler T., Erichsen S., Schiergens T.S., Herrler G., Wu N.H., Nitsche A., Muller M.A., Drosten C., Pohlmann S. SARS- CoV-2 cell entry depends on ACE2 and TMPRSS2 and is blocked by a clinically proven protease inhibitor. Cell. 2020;181(2):271-280. doi: 10.1016/j.cell.2020.02.052. [PMC free article] [PubMed] [CrossRef] [Google Scholar] 
10. CDC. COVID-19: SARS-CoV-2 variant classifications and definitions. Atlanta, GA: US Department of Health and Human Services, 2021. https://www.cdc.gov/coronavirus/2019-ncov/cases-updates/variant-surveillance/variant-info.html

11. Shah PS, Diambomba Y, Acharya G, Morris SK, Bitnun A. Classification system and case definition for SARS-CoV-2 infection in pregnant women, fetuses, and neonates. ActaObstetGynecol Scand. 2020 May;99(5):565-568. doi: 10.1111/aogs.13870. PMID: 32277845; PMCID: PMC7262318

12. .Plante JA, Liu Y, Liu J, Xia H, Johnson BA, Lokugamage KG, Zhang X, Muruato AE, Zou J, FontesGarfias CR, Mirchandani D. Spike mutation D614G alters SARS-CoV-2 fitness. Nature. 2021 Apr;592(7852):116-21.

13. Kirola L. Genetic emergence of B. 1.617.2 in COVID-19.New Microbes and New Infections. 2021 Sep $1 ; 43: 100929$.

14.https://scholar.google.com/scholar?hl=en\&as sdt=0\%2C5\&q=doi\%3A+10.1016\%2FS0262-

4079\%2821\%2901121-0\&btnG=\#: :text=Vaughan\%20A.\%20Delta\%20to\%20dominate\%20world.Vaughan A. Delta to dominate world.

15. Wu D, Wu T, Liu Q, Yang Z.The SARS-CoV-2 outbreak:what we know. International journal of infectious Diseases. 2020 May 1;94:44-8. 